\title{
Numerical Simulation of The Time Effect to Rocks With The Fluid-Structure Coupling Condition
}

\author{
Moli Zhao ${ }^{1,2, a}$, Wen Wang ${ }^{3, b}$ \\ ${ }^{1}$ Department of Engineering Mechanics, School of Civil Engineering, Shandong University, Jinan \\ 250061, PR China; \\ ${ }^{2}$ Geotechnical and Structural Engineering Research Center, Shandong University, Jinan 250061, \\ Shandong, PR China \\ ${ }^{3}$ Shandong Urban Construction Vocational College, Jinan, Shandong, 250103, PR China \\ ahello-zml@163.com, ${ }^{b}$ sddxww@126.com
}

\begin{abstract}
Keywords: Fluid-Structure Coupling Conditions; Rheology model; Numerical simulation; Finite Difference Method

Abstract. The solid and fluid phases are not miscible phases while solid deformation and fluid transport are generally coupled processes. On long time scales, fluids allow stress-driven creep in the middle rock mass with the constant pressure. This paper aims to demonstrate time effect to rocks with the fluid-structure coupling conditions by using the finite difference simulation. It is shown that the results of numerical simulation are matched to that of the previous laboratory tests.
\end{abstract}

\section{Introduction}

Fluids permeate the pores and cracks of crustal rocks and often have a significant effect on rock deformation and failure under stress. One of the mechanical roles of aqueous pore fluid on rock mass is to weaken and embrittle rocks. Previous studies have shown that brittle strength of a rock is generally reduced in the presence of water [1,2]. Baud et al.[3] demonstrated that water-weakening effects in both regimes can be explained consistently by micromechanical models formulated on the basis that the specific surface energy in the presence of water is lower than that in vacuo. Herber F. Wang [4] using the theory of linear poroelasticity gave the relationship between the poisson's ratio and elastic modulus of the drainage condition and undrained condition which is correspond with the laboratory test of Lorent B.[5] and Yale D.P.[6]. Cristescu N.[7] demonstrated the creep effect with fluid flow. From the laboratory tests result, we can see that fluid can cut down the initial creep deformation and the value of creep model parameters and can also enlarge the creep deformation and the rate of deformation. The finite difference method is used to simulate the creep effect under fluid-structure coupling conditions with the given rheology model in rocks.

\section{Simulation of creep effect under fluid-structure coupling condition}

The calculating mode for fluid and creep are all controlled by the calculating time and the time is the real time. So we need to unify the unit of time. If we use the command slove age for the second step, all the parameters calculating by time like viscosity coefficient should use second unit. If the two calculating configs are given with the same unit of time, we can find the same seepage time and creep time shown on the command window as Fig. 1.

\begin{tabular}{cccccc} 
step & max-unbal & ratio & Creep Time & Fluid. Time Time Step \\
\hline 84619 & $1.798 \mathrm{e}+005$ & $5.993 \mathrm{e}-005$ & $6.245 \mathrm{e}+091$ & $6.245 \mathrm{e}+001$ & $1.056 \mathrm{e}-003$
\end{tabular}

\section{No config fluid simulation}

Fig. 1 Command window shown for creep time and fluid time

Engineering problems such as the underground water, the dam foundation seepage, deep tunnel constructions are all involved in the role of the pore pressure. In flac $3 \mathrm{~d}$ fluid mode, there are two kinds of the calculating model. One is no config fluid command. This model can be given the pore pressure on 
the nodes but its value will not change. However, if the material is plasticity, the crack situation is determined by the effective stress. Here, we will give an example to simulate the fluid flow with no config fluid command. The cylinder sample with $2 \mathrm{~m}$ diameter and $2 \mathrm{~m}$ high of 80 elements with a mohr-coulomb model for plastic deformation is used. The following parameters are assumed in the simulation: bulk modulus $\mathrm{K}=1.19 \times 10^{10} \mathrm{~Pa}$, shear modulus $\mathrm{G}=1.1 \times 10^{10} \mathrm{~Pa}$, cohesion $\mathrm{c}=2.72 \times 10^{5} \mathrm{~Pa}$, angle of internal friction $\varphi=44^{\circ}$, tension limit $\sigma^{\mathrm{t}}=2 \times 10^{5} \mathrm{~Pa}$. Loading on the top and bottom as the velocity $\mathrm{v}=1 \times 10^{-7} \mathrm{~Pa} / \mathrm{s}$ of 3000 steps, the stress-strain curves with different pore pressure are shown in Fig. 2 at the center point of the top surface and the point on the boundary.
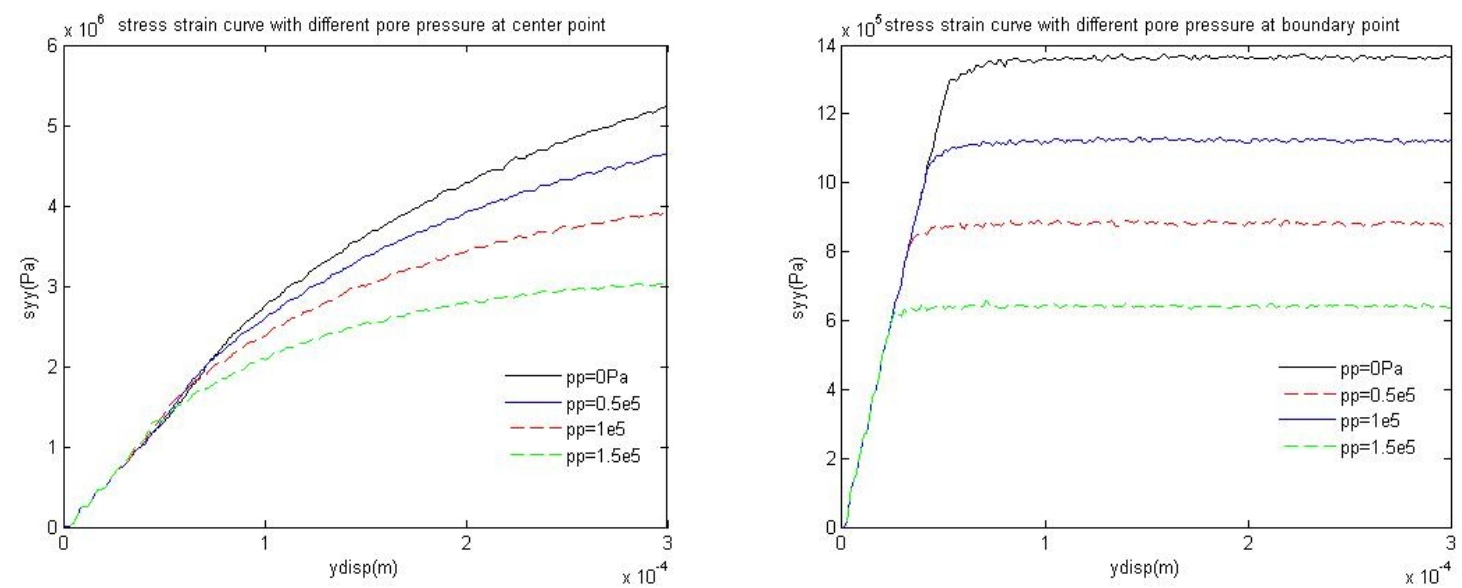

Fig. 2 Stress-strain curves with different pore pressure at center point and boundary point

From the above figures, we can see that the pore pressure is one of the important effects on the strength of the rock under the fluid-structure condition. The existence of the pore pressure reduces the strength of the rock. The displacement with high pore pressure is always more than the low pressure under the same loading.

\section{No config fluid creep simulation}

Take case of the cubic rock with side length $3 \mathrm{~m}$ (see Fig. 3) using model Cvisc which is a viscoplastic creep model combined by burgers model and mohr-coulumb model. Taking the material parameters as elastic bulk modulus $\mathrm{K}=1.19 \times 10^{10} \mathrm{~Pa}$,Maxwell shear modulus $\mathrm{G}^{\mathrm{M}}=1.1 \times 10^{10} \mathrm{~Pa} \quad$,Kelvin shear modulus $\mathrm{G}^{\mathrm{K}}=1.1 \times 10^{10} \mathrm{~Pa}$, Kelvin viscosity $\eta^{\mathrm{K}}=1.1 \times 10^{10} \mathrm{~Pa} . \mathrm{s}$, cohesion $\mathrm{c}=2.72 \times 10^{5} \mathrm{~Pa}$, angle of internal friction $\phi=44^{\circ}$, tension limit $\sigma^{\mathrm{t}}=2 \times 10^{5} \mathrm{~Pa}$, initial pore pressure $\mathrm{p}=1 \times 10^{4} \mathrm{~Pa}$, the loading rate at the first stage is increased to the incipient failure then unload the pressure. In the second stage, the loading rate is set to a higher value than the first one and the sample stays at yield state. Finally the compressive velocity is set to be zero again. The evolution of axial stress at the center point of the model during this whole process can be observed in Fig.3. The mohr-coulumb failure criterion is used for this test. The mohr-coulumb failure criterion is defined as[8]

$$
f=\sigma_{1}-\sigma_{3} N_{\phi}+2 C \sqrt{N_{\phi}}
$$

where $N_{\phi}=(1+\sin \phi) /(1-\sin \phi)$. The time of yield can be also calculated by the stress of yield from the equation

$$
\begin{aligned}
& t=-\sigma_{x x} L /\left(2 v\left(a_{1}-2 a_{2}^{2} /\left(a_{1}+a_{2}\right)\right)\right) \\
& \sigma_{x x}=\left[a_{1}-2 a_{2}^{2} /\left(a_{1}+a_{2}\right)\right] \varepsilon_{x x}
\end{aligned}
$$

where $a_{2}=K+4 / 3 G, a_{2}=K-2 / 3 G, \varepsilon_{x x}=-2 v t / L, v$ is the loading speed.

In the above case, the time of yield is $0.762 \mathrm{~s}$ and the timestep is 762 with $\mathrm{dt}=1 \times 10^{3}$ using mohr model. However, the time of yield is $1 \mathrm{~s}$ and the timestep is 1000 with $\mathrm{dt}=1 \times 10^{3} \mathrm{using}$ cvisc model. The yield time with the pore pressure will be higher than no pore pressure both in creep model or not. The yield strength can be calculated with $-2 C \sqrt{N_{\phi}}$ which equals $-1.28 \times 10^{6} \mathrm{~Pa}$ and the yield time is $1 \mathrm{~s}$. If we 
consider the fluid flow, the yield strength is $1.239 \times 10^{6} \mathrm{~Pa}$ and the creep time is $0.95 \mathrm{~s}$ which is $96.5 \%$ over the no fluid flow condition. After the load is set to zero for $500 \mathrm{step}$, the stress is falling to $1.12 \times 10^{6} \mathrm{~Pa}$ with fluid flow that is higher than the stress $1.16 \times 10^{6} \mathrm{~Pa}$ with no fluid flow. So this can be also corresponded to the test. The existence of fluid flow have many influence to the properties of the materials like reducing the yield strength, shortening the time to yield, lowering the residual strength and decreasing the displacement of reaching the yield stress.
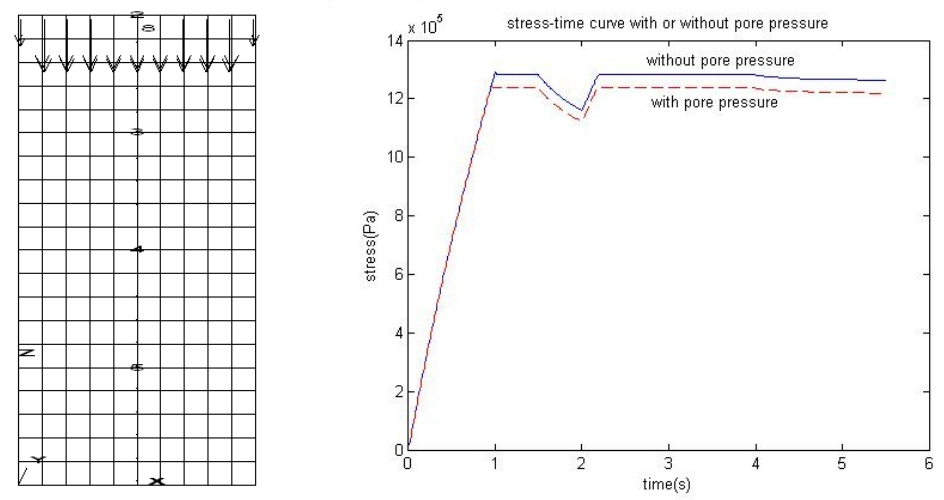

Fig. 3 Finite difference grid and its stress-strain curves with or without pore pressure

\section{Config fluid creep simulation}

If the command config fluid is given, a transient fluid-flow analysis can be performed, and change in pore pressures can occur, as well as change in the phreatic surface. Both effective-stress (static pore-pressure distribution) and undrained calculations can be carried out in config fluid mode. In addition, a fully coupled analysis can be performed, in which changes in pore pressure generate deformation, and volumetric strain causes the pore pressure to evolve. If the command config creep is also given, the creep effect with the fluid-structure can be analyzed. In order to illustrate this effect, a uniaxial compression test will be given under fluid-structure coupled condition with Cvisc rheology model.

The sample is selected as a cuboid with $10 \mathrm{~cm}(\mathrm{x}) \times 20 \mathrm{~cm}(\mathrm{y}) \times 1 \mathrm{~cm}(\mathrm{z})$ of 200 elements and 462 nodes (see Fig. 4 ). The cuboid is subjected to a rapidly applied pressure on the top of it that is held constant for a long period of time. The boundaries are "fixed" only in the specified y-direction on the bottom of the sample. The Cvisc rheology model has the properties: bulk modulus $\mathrm{K}=3 \times 10^{10} \mathrm{~Pa}$, Kelvin shear modulus kshear $=4 \times 10^{10} \mathrm{~Pa}$, Maxwell shear modulus mshear $=5 \times 10^{10} \mathrm{~Pa}$, Kelvin viscosity kvisc $=10 \times 10^{10} \mathrm{~Pa} \cdot \mathrm{d}$. The same sample is used in different simulations with three different kinds of conditions to demonstrate the time effect.

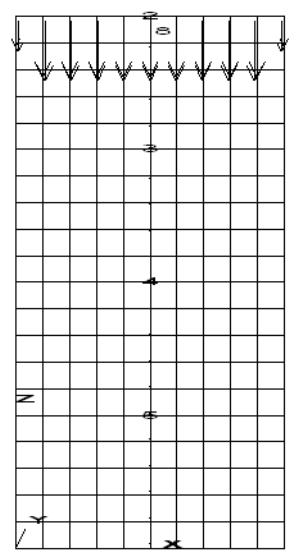

Fig. 4 Cuboid mesh model

One is loading on the top of the sample that is held constant of $40 \mathrm{MPa}, 50 \mathrm{MPa}, 60 \mathrm{MPa}, 70 \mathrm{MPa}$ for 20 days with no pore pressure ; Second test is loading on the top of the sample that is held constant of 40MPa , $50 \mathrm{MPa}, 60 \mathrm{MPa}, 70 \mathrm{MPa}$ for 20 days given undrained config fluid; Last test is loading on the top of the sample that is held constant of $40 \mathrm{MPa}, 50 \mathrm{MPa}, 60 \mathrm{MPa}, 70 \mathrm{MPa}$ for 20 days given 
drainage condition with full coupled config fluid. The Z-displacement of instantaneous deformation and creep deformation with different conditions at some given monitoring points are given in Table 1.

Table 1 Deformations with different conditions at monitoring points

\begin{tabular}{|c|c|c|c|c|c|c|}
\hline \multirow{2}{*}{$\begin{array}{c}\text { Type of } \\
\text { deformation }\end{array}$} & \multirow{2}{*}{ Time[d] } & \multirow{2}{*}{ State } & \multicolumn{4}{|c|}{ Z-displacement Monitoring [mm] } \\
\hline & & & Point 2 & Point 3 & Point 4 & Point 5 \\
\hline \multirow{3}{*}{$\begin{array}{l}\text { Instantaneous } \\
\text { deformation }\end{array}$} & $9.64 \mathrm{E}-17$ & dry & 0.06216 & 0.04661 & 0.03106 & 0.01553 \\
\hline & $1.08 \mathrm{E}-16$ & undrained & 0.06206 & 0.04649 & 0.03094 & 0.01539 \\
\hline & $1.08 \mathrm{E}-16$ & drainage & 0.06206 & 0.04649 & 0.03094 & 0.01539 \\
\hline \multirow{25}{*}{$\begin{array}{l}\text { Creep } \\
\text { deformation }\end{array}$} & \multirow{5}{*}{20} & dry & 0.11100 & 0.08298 & 0.05495 & 0.02692 \\
\hline & & undrained & 0.11200 & 0.08380 & 0.05563 & 0.02723 \\
\hline & & increment & 0.00100 & 0.00082 & 0.00068 & 0.00031 \\
\hline & & drainage & 0.11180 & 0.08323 & 0.05511 & 0.02699 \\
\hline & & increment & 0.00080 & 0.00025 & 0.00016 & 0.00007 \\
\hline & \multirow{5}{*}{40} & dry & 0.14820 & 0.11070 & 0.07330 & 0.03593 \\
\hline & & undrained & 0.14940 & 0.11170 & 0.07410 & 0.03628 \\
\hline & & increment & 0.00120 & 0.00100 & 0.00080 & 0.00035 \\
\hline & & drainage & 0.14860 & 0.11080 & 0.07331 & 0.03593 \\
\hline & & increment & 0.00040 & 0.00010 & 0.00001 & 0.00000 \\
\hline & \multirow{5}{*}{60} & dry & 0.18540 & 0.13840 & 0.09167 & 0.04493 \\
\hline & & undrained & 0.18680 & 0.13950 & 0.09256 & 0.04532 \\
\hline & & increment & 0.00140 & 0.00110 & 0.00089 & 0.00039 \\
\hline & & drainage & 0.18570 & 0.13840 & 0.09161 & 0.04489 \\
\hline & & increment & 0.00030 & 0.00000 & -0.00006 & -0.00004 \\
\hline & \multirow{5}{*}{80} & dry & 0.22270 & 0.16610 & 0.11000 & 0.05392 \\
\hline & & undrained & 0.22380 & 0.16730 & 0.11100 & 0.05435 \\
\hline & & increment & 0.00110 & 0.00120 & 0.00100 & 0.00043 \\
\hline & & drainage & 0.22280 & 0.16600 & 0.10990 & 0.05385 \\
\hline & & increment & 0.00010 & -0.00010 & -0.00010 & -0.00007 \\
\hline & \multirow{5}{*}{100} & dry & 0.25980 & 0.19400 & 0.12850 & 0.06304 \\
\hline & & undrained & 0.26170 & 0.19570 & 0.13000 & 0.06377 \\
\hline & & increment & 0.00190 & 0.00170 & 0.00150 & 0.00073 \\
\hline & & drainage & 0.26040 & 0.19410 & 0.12860 & 0.06309 \\
\hline & & increment & 0.00060 & 0.00010 & 0.00010 & 0.00005 \\
\hline
\end{tabular}

It is shown in Table 1 that the time used to reach initial equilibrium both in undrained and drainage condition are less than that of dry condition, while the instantaneous deformations are more than later. Because of the existence of pore in dry rock, the pore will be closed in an instant under compression. However, water can be considered as incompressible fluid in saturated rocks. Therefore, water cannot afford time to spread with instantaneous compression shown as higher compression strength with lower deformation. The result is corresponding with the laboratory uniaxial compression test. The results, presented in Tables 1, indicate both drainage and undrained condition the deformation of creep is larger than that of dry condition, which means water promoted the rock creep deformation. This result is also the same with the laboratory test. Nevertheless, creep deformation under the drainage condition is smaller than that of undrained condition. The state of the undrained creep deformation incremental decreases with the increase of the depth, increases with the increase of the pressure. The drainage condition of creep deformation incremental decreases with the increase of the depth, under low axial compression decreases with the increase of the pressure, but under high axial compression increases. 


\section{Conclusions}

In this paper, we used three cases to demonstrate the time effect to rocks with the fluid-structure coupling conditions by using the finite difference method. It is shown that the results of numerical simulation are matched to the previous laboratory test results. Water can promote the rock creep deformation. The creep deformation is connected with the undrained and drainage condition.

\section{Acknowledgements}

This work was financially supported by the Shandong Provincial Natural Science Foundation (No. ZR2015EQ005), The Fundamental Research Funds of Shandong University (No.2015GN030). China Postdoctoral Science Foundation funded project (No. 2015M582092).

\section{References}

[1] H. F. Wang: Mechanics of Fluid-Saturated Rocks. Elsevier Academic Press. (2004).

[2] Y. Gueguen, V.V. Palciauskas: Introduction to the Physics of Rocks, Princeton University Press, (1994).

[3] P. Baud, W. Zhu, T. Wong: J Geophs Res: Solid Earth (1978-2012). Vol. 105(B7) (2000), p.16371-p.16389.

[4] HF Wang: Theory of linear poroelasticity: With applications to geomechanics and hydrogeologoy. Princeton University Press, (2000).

[5] B. Loret, E. Rizzi, Z. Zerfa. J Mech Phys Solids. Vol. 49(11) (2001), p.2593-p.2619.

[6] D. Yale: Static and dynamic rock mechanical properties in the hugoton and panoma fields, kansas. (1994).

[7] N. Cristescu, U. Hunsche: Time effects in rock mechanics. Wiley New York, (1998).

[8] Itasca Consulting Group Inc, FLAC3D-fast Lagrangian analysis of continua in 3 dimensions. Ver.

3.1 user's manual. ICG, Minneapolis, (2006). 